\title{
Segmentation of Medical X-ray Bone Image Using Different Image Processing Techniques
}

\author{
Folasade Olubusola Isinkaye ${ }^{1}$, Abiodun Gabriel Aluko ${ }^{2}$, Olayinka Ayodele Jongbo ${ }^{3}$ \\ ${ }_{1,2,3}$ Department of Computer Science, Ekiti State University, Ado-Ekiti, Nigeria. \\ Email: ${ }^{1}$ folasade.isinkaye@eksu.edu.ng, ${ }^{2}$ gabrielaluko29@ gmail.com, ${ }^{3}$ yinkutech1@ gmail.com
}

Received: 09 June 2021; Accepted: 28 July 2021; Published: 08 October 2021

\begin{abstract}
Accurate medical image processing plays a crucial role in several clinical diagnoses by assisting physicians in timely treatment of wounds and mishaps. Medical doctors in the hospitals generally rely on examining bone $\mathrm{x}$-ray images based on their expertise, knowledge and past experiences in determining whether a fracture exist in bone or not. Nevertheless, majority of fractures identification methods using X-rays in the hospitals is beyond human understanding due to variation in different attributes of fracture and complication of bone organization thereby making it difficult for doctors to correctly diagnose and proffer adequate treatment to patient ailments. The need for robust diagnostic image processing techniques for image segmentation for different bone structures cannot be overemphasized. This research implemented different image segmentation techniques on a bone x-ray image in order to identify the most efficient for timely medical diagnosis. Also, the strength and weaknesses of the diverse segmentation techniques were also identified. This will empowered researchers with appropriate knowledge needed to improve and build better image segmentation models which doctors can use in handling complex medical image processing problems. Also, miss rate in bone X-rays that contains multiple abnormalities can be lowered by using appropriate image segmentation techniques thereby improving some of the labor intensive work of medical personnel during bone diagnosis. MATLAB 9.7.0 programing tool was used for the implementation of the work. The results of X-ray bone segmentation revealed that active contour model using snake model showed the best performance in detecting boundaries and contours of regions of interest when used in segmenting Femur bone image than the other medical image segmentation approaches implemented in the work.
\end{abstract}

Index Terms: Image Processing, Image Segmentation, Thresholding, Edge-based, Region-based technique, Deformable Model

\section{Introduction}

Image segmentation is one of the most difficult tasks in image processing. Conventionally, image segmentation is generally done by a radiologist and it is taking as the gold standard. This approach is distinguished as it can exploit expert knowledge. However, the challenges of the approach are, it wastes a lot of time, it is not very precise and it is open to inter-observer and intra-observer variability [1]. In traditional image segmentation approach, image is distinguished by the nature of the intensity, contour and texture. However, there are many cases in which some of the approaches used in determining the constituent of the images will not be functional thereby making it difficult to infer from one problem to another. Also, traditional image segmentation wastes a lot of time during processing which reduces the performance accuracy of image measurements. In recent times, researchers have moved from traditional methods of Image segmentation to more advanced methods of image segmentation such as edge based detection, thresholding, region growing and deformable model [2]. These methods help to partition images into numerous parts based on some specific features such as intensity value, color, texture and etc. Also, they are largely based on features which are similarity and discontinuity. Methods based on similarity are called Region based approaches while methods based on discontinuities are called boundary based approaches.

Medical image segmentation is the process of forming visual representations of the internal parts of a body [3,4] needed in scientific analysis for making intelligent diagnostic decisions. Medical image processing seeks to reveal the internal structures of the objects and analysis obtained from these discoveries can be used by physician in proffering solution to patient's ailment. medical image processing is an important area of interest in health care industries based on the fact that majority of medical images contains vital information about patients cases which tends to improve visualization of human anatomy [5,6]. Automated image processing is a way of improving the accuracy of image segmentation procedures using the algorithm that take images as input and return image as output by extracting necessary information from the image. In this process, image needs to be reduced to certain defining characteristics and the analysis of these image attributes gives relevant information for making diagnostic decisions [7]. Segmentation aims 
to split image into regions, based on the characteristics of the image that are relatively constant in each region. Generally, segmentation purpose is to extract important information from medical imaging. Medical image processing in bone structures has improved majorly in the areas of medical diagnoses that can be used by medical personnel in studying the anatomical structures of the image needed in determining the best treatment plan to be given to patient [8].

Femur X-ray medical image is useful for many medical studies such as diagnosis, surgery and treatment. However, segmentation of Femur bone X-ray images is a crucial task in automatic study of medical images and orthopedic inspections. It is more challenging than segmenting computed Tomography (CT) and Magnetic Resonance (MR) images because some of the lower density similar tissues are difficult to differentiate from the femur in X-ray images. Despite many years of studying medical bone images, its segmentation still remains an open issue in different areas.

Although, there exist recent segmentation techniques to address medical image segmentation problems, there is still no fit all among them for segmenting medical images. Each imaging technique has its peculiar constraints. Therefore, this work tried to implement different image segmentation techniques to identify the best for segmenting femur X-ray image. This will assist medical experts to be able to use suitable technique to quickly extract valuable details from medical images and hence, improves the precision of clinical diagnosis as well as timely treatment of patients.

The rest of the paper is organized as follows; section 2 gives the details of related work and techniques used in image processing for medical images. Section 3 presents the methodology as well as result and discussions, while the rest of the section gives the conclusion, recommendation and suggestions for future work.

\section{Related Work}

This section presents literatures of existing methods used in image segmentation in recent years. Most of this work showed promising results based on techniques used. For example, in Osama et al [9], an algorithm to segment organs of human body from CT scans using automated image processing technique was proposes. The authors employed Binary Mask generations and Otsu thresholding to convert grayscale images with colors intensities from 0 to 255 to white and black pixels. Mathematical morphology, distance transform, marker-controlled technique, and watershed transform was also used in their approach, result proved the efficiency of image segmentation in enhancing the procedures and the workflow of the radiological examination. Zhao et al [10] developed a versatile framework for medical image processing using deep learning approach. The study employed RSNA dataset generative adversarial network (GAN) and class active map was used for image processing. Result of mean average error (MAE) of 5.991 and 6.263 months on male and female cohorts was achieved, comparable to the state-of-the-art performance on a large-scale dataset which can be effectively applied to medical image processing task. Also, A study was carried out in [11,12] on image segmentation using hybrid segmentation approach. The work used a locally adaptive thresholding technique that removes background noise by using local mean and standard deviation. Result showed that Niblack algorithm is better than the Sauvola algorithm in removing background noise from an image

Farmaha et al [13] carried out their study on image segmentation using clustering algorithms based on artificial neural network (ANN) for identifying bio-medical images that can automate wound area selection. Result showed that clustering algorithm could accurately be used to determine the precise assessment and measurement of wound in determining the effective treatment for medical diagnosis. However, due to high dependence of artificial neural network on training data, the heterogeneity of training images affects the allocation of features and segmentation. For better results, more homogeneous images are required. Bansal et al [14] developed a hybridization approach for segmentation of brain tumor to locate the digital pixel in the brain from MRI image. Using swarm optimization (PSOA) algorithm and swarm ant lion method to improve the PSNR value for early detection of brain tumor that could enhance patient lives. Parameters like image quality (PSNR), error rate (MSE) and accuracy rate (ACC) were used in model evaluation. Accuracy of $98.58 \%$.was achieved using hybridization algorithm for detection of brain tumor. In the work of Tian et al [15], they proposed image segmentation method based on deep reinforcement learning algorithm. Segmentation process is formulated as a Markov decision process and solved by a deep reinforcement learning (DRL) algorithm, which trains an agent for segmenting ROI in images. The agent performs a serial action to delineate the ROI. Experimental result revealed that the proposed method has $7.24 \%$ improved to the state-of-the-art method on three prostate MR data sets and has $3.52 \%$ improved on one retinal fundus image data set. Kant and Bala [16] focused on generalize encoderdecoder model called dense dilated inception network (DDI-Net) for medical image segmentation. The study used dense path to replace the skip connection in the middle of the encoder and decoder to make the model deeper and replace the U-net basic convolution blocks with a Multi-scale dilated inception module in making the model wider. Experiment result showed that the proposed approach had a better result that can be used for image segmentation with a Dice score of 0.82 and 0.95 for brain tumor and heart segmentation respectively.

Ouyang et al [17] developed a self-supervised few-shot segmentation framework for medical imaging to address the problem of existing techniques due to lack of annotations. The study employed adaptive local prototype pooling module plugged into prototypical networks, to solve foreground-background imbalance problem in medical image segmentation. The general applicability of the proposed study was carried out using abdominal organ segmentation as well as cardiac segmentation for CT and MRI. Haider, et al [18] presented a hybrid method for edge continuity based on 
pixel Neighbors pattern analysis. The authors used Sobel edge detector in detecting edges with noise-suppression property after which, Otsu thresholding technique was used for localization of background and foreground pixels. Experiments result revealed that the proposed technique outperform NN-based approach to segmentation in terms of accuracy and processing time. Samet et al [19] proposed a new Fuzzy Rule-based image segmentation technique to segment thin images in rock. The study used RGB image of rock thin segment as input and mineral image as output and applied Fuzzy C Means on rock thin images for image processing Result showed that the proposed approach was better than the existing algorithms used in this area. Khokher et al [20] presented a new approach of image segmentation using Fuzzy Rule based system and Graph Cut to segment the gray scale, color, and texture images. Fuzzy rules were used in assigning weight to the features of the images. Evaluation was carried out using Mean, Standard Deviation, and PPV value. Result showed that proposed approach achieved a better result of 0.85 to 0.95 for S.D and PPV respectively. Li et al [21] suggested an image segmentation technique that improvises the performance parameters of (CCQPSO) algorithm to overcome the performance of CCQPSO algorithm having lesser convergence rate and slow searching speed. The study used partitioned and cooperative quantum based PSO technique to overcome these issues by coupling the two techniques for efficient segmentation. This approach improvises convergence and avoids trapping into local optima. Result revealed that the proposed method improves segmentation with multiple thresholds.

Rouhi et al [22] classified breast tumors using region growing and CNN segmentation techniques for generating adaptive thresholds and templates for conserving tumor boundaries. Five classification algorithms such as random forest, support vector machine, KNN, MLP and naïve Bayes were used for prediction. The proposed approach was tested on publicly available (DDSM and MIAS) dataset consisting of 219 images of malignant and benign patient respectively. Experimental result yield accuracy of $96.47 \%$ and showed that CNN segmentation algorithm help in efficient classification of breast tumors. Tyan et al [23] identified several image segmentation methods for effective detection of ischemic stroke or embolus in brain. The author focused on image in frequency-time domain and applied various measures for detection of emboli in brain. Comparisons were made among the model to determine the best performing model. Evaluation result revealed that SM modeling has $84.2 \%$ acceptance rate for estimating stroke area. An approach of segmenting medical images was proposed in [24] using unsupervised learning and calculating local center of mass of an image signal. In the study, pixels were assembled into regions based on their center of mass. The authors compared their approach with other existing methods such as watershed method, SLIC and GMM-HMRF. Result showed that their approach produces promising result and better boundaries between regions by attaining the highest optimal dice score which outperformed other existing unsupervised methods used in segmenting medical images.

Different image segmentation approaches have been used by different authors to segment diverse image parts and have each reported to be successful according to the reviews. In this paper, we investigated different image segmentation techniques on femur bone image in order to identify the most promising out of them all that can handle femur image segmentation problems accurately.

\subsection{Medical Image Segmentation Techniques.}

Dar and Padha [25] highlighted various approaches that can be used in image processing for medical image segmentation as follows:

i. Segmentation by Clustering: Clustering algorithm helps to improve the performances accuracy of the models used in medical image segmentation. The used of clustering technique is still a challenging issue in image processing as this approach cannot be used to solve all segmentation problems. However, many studies have used this approach to solve classification problems as highlighted in Table 1.

Table 1. Clustering techniques used in image segmentation

\begin{tabular}{|c|c|c|c|c|c|}
\hline $\mathrm{S} / \mathrm{N}$ & Author/year & Method & Result & Limitation & Future improvement \\
\hline 1 & Li et al, [26] & $\begin{array}{l}\text { fuzzy clustering with } \\
\text { cellular automata (CA) } \\
\text { and features weighting }\end{array}$ & $\begin{array}{l}\text { Fast convergence speed, } \\
\text { strong anti-noise property, } \\
\text { and robustness. Ability to } \\
\text { effectively segment } \\
\text { common images and long- } \\
\text { term sequence satellite } \\
\text { remote sensing images and } \\
\text { has good applicability. }\end{array}$ & $\begin{array}{l}\text { The determination of } \\
\text { fuzzy membership is } \\
\text { tasking. }\end{array}$ & $\begin{array}{l}\text { More image features } \\
\text { to be utilized in the } \\
\text { system, identification. } \\
\text { of optimal feature } \\
\text { combination, more } \\
\text { efforts to improve the } \\
\text { segmentation speed } \\
\text { and efficiency. }\end{array}$ \\
\hline 2 & $\begin{array}{l}\text { (Lei et al, } \\
{[27]}\end{array}$ & $\begin{array}{lr}\text { Automatic } & \text { fuzzy } \\
\text { clustering } & \text { framework } \\
\text { for } & \text { image } \\
\text { segmentation r by } \\
\text { integrating super pixel } \\
\text { algorithms, density } \\
\text { peak clustering, and } \\
\text { prior entropy. }\end{array}$ & $\begin{array}{l}\text { Accurate numbers of } \\
\text { clusters were obtained } \\
\text { through the system. It } \\
\text { produced the best } \\
\text { segmentation results than } \\
\text { the state of the art. }\end{array}$ & $\begin{array}{l}\text { It is computationally } \\
\text { intensive. }\end{array}$ & $\begin{array}{l}\text { Convolutional neural } \\
\text { networks can be used } \\
\text { to extract image } \\
\text { features and feature } \\
\text { learning algorithm can } \\
\text { be explored to achieve } \\
\text { better automatic } \\
\text { image segmentation. }\end{array}$ \\
\hline
\end{tabular}




\begin{tabular}{|c|c|c|c|c|c|}
\hline 3 & $\begin{array}{l}\text { (Qureshi } \\
\text { and Ahamad, } \\
{[28]}\end{array}$ & $\begin{array}{l}\text { Clustering technique } \\
\text { with Neutrosophy was } \\
\text { used to solve the } \\
\text { problem } \\
\text { indeterminacy factor } \\
\text { of image pixels }\end{array}$ & $\begin{array}{l}\text { Better results on synthesis } \\
\text { image and real images } \\
\text { with/without noise. }\end{array}$ & $\begin{array}{l}\text { The approach may } \\
\text { not work well on a } \\
\text { non- global clusters }\end{array}$ & $\begin{array}{lr}\text { Neutrosophy } & \text { can be } \\
\text { applied to other image } \\
\text { processing problems } \\
\text { such as feature } \\
\text { extraction } r \text { and } \\
\text { classification }\end{array}$ \\
\hline 4 & $\begin{array}{l}\text { Bora and } \\
\text { Gupta [29] }\end{array}$ & $\begin{array}{l}\mathrm{K}-\text { means clustering } \\
\text { with cosine distance } \\
\text { measure. }\end{array}$ & $\begin{array}{l}\text { An efficient result of color } \\
\text { image segmentation }\end{array}$ & $\begin{array}{l}\text { The approach may } \\
\text { not adequately detect } \\
\text { blurred image }\end{array}$ & $\begin{array}{l}\text { An } \\
\text { clustering technique } \\
\text { with a good } \\
\text { determines number of } \\
\text { clusters may be } \\
\text { considered for better } \\
\text { segmentation result. }\end{array}$ \\
\hline 5 & $\begin{array}{l}\text { Hassan et al, } \\
\{30]\end{array}$ & $\begin{array}{l}\text { K-means clustering } \\
\text { combined with RGB } \\
\text { and HSV color spaces }\end{array}$ & $\begin{array}{l}\text { Accurate segmentation } \\
\text { result of RGB and HSV } \\
\text { color spaces compared to } \\
\text { segmentation of single } \\
\text { color space }\end{array}$ & $\begin{array}{l}\text { The algorithm may } \\
\text { not be able to detect } \\
\text { all colors. }\end{array}$ & 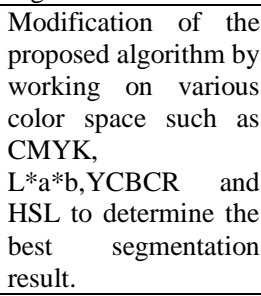 \\
\hline 6 & $\begin{array}{l}\text { Saravanan et } \\
\text { al, [31] }\end{array}$ & 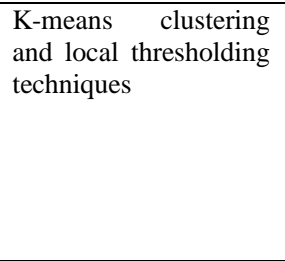 & $\begin{array}{l}\text { Good segmentation } \\
\text { performance is achieved } \\
\text { using K-means clustering } \\
\text { than thresholding method } \\
\text { on mammographic images. }\end{array}$ & $\begin{array}{l}\text { Difficult in predicting } \\
\text { the value of } \mathrm{K} \text { with } \\
\text { fixed number of } \\
\text { clusters }\end{array}$ & $\begin{array}{l}\text { Improved k-means } \\
\text { algorithms and other } \\
\text { clustering methods } \\
\text { can be applied for } \\
\text { more accurate } \\
\text { classifications in } \\
\text { mammographic } \\
\text { images }\end{array}$ \\
\hline 7 & Panda [32] & $\begin{array}{l}\text { Comparative analysis } \\
\text { of K-means clustering } \\
\text { and thesholding } \\
\text { technique. }\end{array}$ & $\begin{array}{l}\text { Low computational time, } \\
\text { increase in clusters size } \\
\text { and more accurate } \\
\text { segmentation quality using } \\
\text { K-means }\end{array}$ & $\begin{array}{l}\text { Low convergence } \\
\text { Time }\end{array}$ & $\begin{array}{l}\text { K-means clustering } \\
\text { can be applied to } \\
\text { applications such as } \\
\text { video retrieval and } \\
\text { face recognition } \\
\text { system }\end{array}$ \\
\hline 8 & $\begin{array}{l}\text { Dubey et al } \\
{[33]}\end{array}$ & K- means clustering & $\begin{array}{l}\text { Low computational cost } \\
\text { and robust technique for } \\
\text { defected area of fruits } \\
\text { segmentation }\end{array}$ & $\begin{array}{l}\text { High memory } \\
\text { management }\end{array}$ & $\begin{array}{l}\text { Machine learning } \\
\text { algorithms can be } \\
\text { used to determine the } \\
\text { number of clusters to } \\
\text { segment the defected } \\
\text { fruits more } \\
\text { effectively. ma }\end{array}$ \\
\hline 9 & $\begin{array}{l}\text { Inbarani et } \\
\text { al, [34] }\end{array}$ & $\begin{array}{l}\text { Hybrid } \\
\text { histogram-based soft } \\
\text { covering rough k- } \\
\text { means clustering } \\
\text { (HSCRKM) technique }\end{array}$ & $\begin{array}{l}\text { The algorithms accurately } \\
\text { segment the nucleus with } \\
\text { improved accuracy using } \\
\text { logistic regression and } \\
\text { neural network algorithms } \\
\text { for detection. }\end{array}$ & $\begin{array}{lr}\text { Require } & \text { more } \\
\text { processing } & \text { time for } \\
\text { multiple } & \text { color } \\
\text { images. } & \end{array}$ & $\begin{array}{l}\text { Future work can use } \\
\text { Bio-inspired } \\
\text { algorithms to improve } \\
\text { the number } \\
\text { of clusters. }\end{array}$ \\
\hline 10 & $\begin{array}{l}\text { Wang and } \\
\text { Zhang [35] }\end{array}$ & $\begin{array}{l}\text { K-Means algorithms } \\
\text { based on internet of } \\
\text { things }\end{array}$ & $\begin{array}{l}\text { Robust techniques for } \\
\text { segmentation of plant } \\
\text { disease in leaf images, }\end{array}$ & $\begin{array}{l}\text { The algorithm may } \\
\text { not work well on a } \\
\text { non-global cluster } \\
\text { leaf images }\end{array}$ & 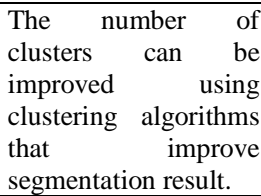 \\
\hline
\end{tabular}

Clustering algorithms is an efficient technique that is robust and computationally faster when the clusters are global. The technique is used in image processing for its simplicity of implementation and convergence speed. The limitations of the algorithms are based on its time complexity which is high and does not work well on non-global clusters. Sometimes, it is difficult in predicting the value of $\mathrm{K}$ with fixed numbers of clusters which may affect segmentation outputs.

ii. Region Growing: This method of segmentation is used to extract a specific region from pre-existing image based on some characteristics such as intensity level inhomogeneity or edges in an image among others [21]. This method requires prior information for selecting a seed pixel. The seed point or pixel is selected by an operator and then pixels that share a unique characteristic such that we can grow a seed pixel in an image till an edge is detected. The region growing technique is never used alone but it is usually combined with set of image processing operations for visualization of small, simple and delicate regions in tumors and lesions. Sometimes region growing method can be sensitive to noise which may affect the accuracy of image segmentation. Various studies conducted using this approach is shown in Table 2. 
Table 2.Region growing techniques used in image segmentation

\begin{tabular}{|c|c|c|c|c|c|}
\hline $\mathrm{S} / \mathrm{N}$ & Author/year & Method & Result & Limitation & Future Work \\
\hline 1 & $\begin{array}{l}\text { Shimodaira } \\
\text { [36] }\end{array}$ & $\begin{array}{l}\text { Seeded region growing } \\
\text { and merging image } \\
\text { segmentation centered } \\
\text { on square elemental } \\
\text { regions. }\end{array}$ & $\begin{array}{l}\text { Reduction in time } \\
\text { complexity and good } \\
\text { segmentation output with } \\
\text { a small number of } \\
\text { regions. }\end{array}$ & $\begin{array}{l}\text { The resolution of the } \\
\text { segmentation outputs does } \\
\text { not capture objects of } \\
\text { regions smaller than } \\
\text { single square elemental } \\
\text { regions. }\end{array}$ & $\begin{array}{l}\text { Future work can be done } \\
\text { using a segmentation } \\
\text { technique that will } \\
\text { capture all regions of the } \\
\text { image rather than } \\
\text { dividing it into sub } \\
\text { regions }\end{array}$ \\
\hline 2 & Yuan [37] & $\begin{array}{l}\text { 3D segmentation of } \\
\text { human femur using } \\
\text { region } \\
\text { algorithms. }\end{array}$ & $\begin{array}{l}\text { Less computational time } \\
\text { with stable results and } \\
\text { improvement in image } \\
\text { segmentation processes }\end{array}$ & $\begin{array}{l}\text { The segmentation process } \\
\text { may not actually capture } \\
\text { all ROIs due to its } \\
\text { resolution. }\end{array}$ & $\begin{array}{l}\text { Developing a high- } \\
\text { resolution image } \\
\text { segmentation method that } \\
\text { can capture all hidden } \\
\text { joints in bone regions }\end{array}$ \\
\hline 3 & $\begin{array}{l}\text { Kaur and } \\
\text { Jindal [38] }\end{array}$ & $\begin{array}{lr}\text { Region } & \text { growing } \\
\text { algorithm inside } & \text { GPU } \\
\text { using Parallel Best } \\
\text { Fitting and Parallel } \\
\text { Local Mutual Best } \\
\text { Fitting techniques. }\end{array}$ & $\begin{array}{l}\text { A better segmented } \\
\text { image with the best } \\
\text { performance obtained } \\
\text { using Parallel Local } \\
\text { Mutual Best Fitting } \\
\text { techniques }\end{array}$ & $\begin{array}{l}\text { The algorithms cannot } \\
\text { handle a wide range of } \\
\text { weighting function on } \\
\text { each image region. }\end{array}$ & $\begin{array}{l}\text { Combining } \\
\text { growing with other } \\
\text { algorithms such as } \mathrm{N} \text {-cut } \\
\text { method of pixel based } \\
\text { segmentation to reduce } \\
\text { the time complexity of } \\
\text { image segmentation } \\
\text { processes. }\end{array}$ \\
\hline 4 & $\begin{array}{l}\text { Jaber et al } \\
{[39]}\end{array}$ & $\begin{array}{lr}\text { Region } & \text { growing } \\
\text { segmentation } & \text { using } \\
\text { double } & \text { filtering } \\
\text { techniques for data } & \\
\text { preprocessing } & \end{array}$ & $\begin{array}{l}\text { A robust segmentation } \\
\text { techniques for breast } \\
\text { cancer detection }\end{array}$ & It is time consuming & $\begin{array}{l}\text { An efficient feature } \\
\text { extraction technique with } \\
\text { a more accurate } \\
\text { segmentation algorithm } \\
\text { can be considered. }\end{array}$ \\
\hline 5 & $\begin{array}{l}\text { Kansal and } \\
\text { Jain [40] }\end{array}$ & $\begin{array}{lr}\text { Automatic } & \text { seed } \\
\text { selection } & \text { algorithm } \\
\text { using region } & \text { growing } \\
\text { segmentation } & \end{array}$ & $\begin{array}{l}\text { It produces original } \\
\text { image having clear edge } \\
\text { with good segmentation } \\
\text { results. }\end{array}$ & $\begin{array}{l}\text { The computational cost is } \\
\text { high. }\end{array}$ & $\begin{array}{l}\text { K-mean algorithm can be } \\
\text { used as a robust } \\
\text { technique for improving } \\
\text { segmentation } \\
\text { performance. }\end{array}$ \\
\hline 6 & $\begin{array}{l}\text { Shewale and } \\
\text { Patil [41] }\end{array}$ & $\begin{array}{ll}\text { Region } & \text { growing } \\
\text { segmentation } & \end{array}$ & $\begin{array}{l}\text { Fast and accurate } \\
\text { segmentation for brain } \\
\text { tumor identification. }\end{array}$ & $\begin{array}{l}\text { It may lead to over } \\
\text { segmentation if the image } \\
\text { is noisy }\end{array}$ & $\begin{array}{l}\text { A robust algorithm of } \\
\text { region } \\
\text { segmentation } \\
\text { combined } \\
\text { with } \\
\text { histogram } \\
\text { thresholding technique } \\
\begin{array}{l}\text { can be used for better } \\
\text { segmentation }\end{array}\end{array}$ \\
\hline 7 & $\begin{array}{l}\text { Biratu et al } \\
{[42]}\end{array}$ & $\begin{array}{l}\text { Modification of region } \\
\text { growing algorithm using } \\
\text { deep learning approach. }\end{array}$ & $\begin{array}{l}\text { The algorithm can } \\
\text { identify brain tumor } \\
\text { locations and extract the } \\
\text { best region of interests. }\end{array}$ & $\begin{array}{l}\text { The proposed technique } \\
\text { cannot adequately select } \\
\text { thresholding points for } \\
\text { region-growing algorithm }\end{array}$ & $\begin{array}{l}\text { Future work can be done } \\
\text { using a deep learning } \\
\text { algorithm that can } \\
\text { overcome the limitations } \\
\text { of existing approaches. }\end{array}$ \\
\hline 8 & $\begin{array}{l}\text { Udayakumar } \\
\text { et al [43] }\end{array}$ & $\begin{array}{l}\text { Comparison of region } \\
\text { growing algorithm with } \\
\mathrm{K} \text { means clustering } \\
\text { technique. }\end{array}$ & $\begin{array}{l}\text { Proposed Region } \\
\text { growing algorithm gives } \\
\text { better accuracy than K- } \\
\text { Means clustering } \\
\text { segmentation for } \\
\text { newborn baby MRI. }\end{array}$ & $\begin{array}{l}\text { High computational } \\
\text { complexity. }\end{array}$ & $\begin{array}{l}\text { Future work can be done } \\
\text { using canny edge based } \\
\text { algorithm and other } \\
\text { convolutional algorithms } \\
\text { to have more accurate } \\
\text { detection. }\end{array}$ \\
\hline 9 & $\begin{array}{l}\text { Jain and } \\
\text { Susan [44] }\end{array}$ & $\begin{array}{l}\text { Adaptive single-seed } \\
\text { based region growing } \\
\text { segmentation algorithm. }\end{array}$ & $\begin{array}{l}\text { A robust algorithm with } \\
\text { good segmentation result } \\
\text { for a wide-ranging } \\
\text { realistic images }\end{array}$ & $\begin{array}{l}\text { High computational cost } \\
\text { and time consuming }\end{array}$ & $\begin{array}{l}\text { A fast and more accurate } \\
\text { algorithm using deep } \\
\text { learning approaches } \\
\text { could be considered. }\end{array}$ \\
\hline 10 & $\begin{array}{l}\text { Thukral et al } \\
\text { [45] }\end{array}$ & $\begin{array}{l}\text { Region growing } \\
\text { algorithm and Median } \\
\text { filter method combined } \\
\text { with Recurrent neural } \\
\text { network algorithm }\end{array}$ & $\begin{array}{l}\text { A robust technique for } \\
\text { identifying the region of } \\
\text { interests with } 97.12 \% \\
\text { accuracy for lung cancer } \\
\text { detection. }\end{array}$ & $\begin{array}{l}\text { Training time for Neural } \\
\text { network is long and time } \\
\text { consuming }\end{array}$ & $\begin{array}{l}\text { An ensemble approach of } \\
\text { machine learning } \\
\text { techniques can be } \\
\text { considered to improve } \\
\text { detection accuracy. }\end{array}$ \\
\hline
\end{tabular}


Region growing segmentation is an efficient technique that works based on partitioning of image into regions, the algorithms are easy to implement, fast, robust, connected regions are guaranteed and clear object boundaries are generated. The drawback lies in the areas of its high computational complexity in memory and time management and may sometimes lead to over segmentation/ under segmentation of images if the object is noisy and not well preprocessed.

iii. Edge based/ boundary based: This segmentation approach deals with identifying and locating boundaries in an image such as edges. The edges are sharp discontinuities which are. Intensity values in an image. This technique is helpful in recognition, disclosure and segmentation of image artifacts. The edge detectors are called 'masks' or 'filters' which are super-imposed over an image to detect discontinuities or boundaries. Review of literatures carried out on this algorithm is highlighted in Table 3.

Table 3. Edge based image segmentation techniques

\begin{tabular}{|c|c|c|c|c|c|}
\hline $\mathrm{S} / \mathrm{N}$ & Author/year & Method & Result & Limitation & Future improvement \\
\hline 1 & $\begin{array}{l}\text { Padmapriya et al } \\
\text { [46] }\end{array}$ & $\begin{array}{l}\text { Edge based image } \\
\text { Segmentation using 2D } \\
\text { ultrasound image. }\end{array}$ & $\begin{array}{l}\text { Reduction } \\
\text { computational time and } \\
\text { improvement in overall } \\
\text { efficiency of the system for } \\
\text { detecting bladder } \\
\text { boundaries }\end{array}$ & Sensitivity to noise & $\begin{array}{l}\text { A 3D ultrasound image may be } \\
\text { used on classical models of the } \\
\text { proposed algorithm to improve } \\
\text { accuracy of detection }\end{array}$ \\
\hline 2 & Kharoffa [47] & $\begin{array}{l}\text { Performance evaluation of } \\
\text { seven edge detection } \\
\text { techniques by measuring } \\
\text { the structural content of } \\
\text { the original image. }\end{array}$ & $\begin{array}{l}\text { Canny edge detection } \\
\text { algorithm achieved better } \\
\text { result as compared to other } \\
\text { methods }\end{array}$ & $\begin{array}{l}\text { It is computationally } \\
\text { intensive }\end{array}$ & $\begin{array}{l}\text { Future work can consider an } \\
\text { algorithm that is less sensitive to } \\
\text { noise to improve segmentation } \\
\text { result. }\end{array}$ \\
\hline 3 & Cao et al, [48] & $\begin{array}{l}\text { Edge } \\
\text { segmentation based } \\
\text { on the Otsu-canny } \\
\text { operator on the hadoop } \\
\text { platform }\end{array}$ & $\begin{array}{l}\text { Improved time reduction } \\
\text { and better edge detection } \\
\text { technique than existing } \\
\text { traditional edge detection } \\
\text { algorithms }\end{array}$ & It is time consuming & $\begin{array}{l}\text { An efficient algorithm that can } \\
\text { handle real-time large-scale image } \\
\text { edge detection segmentation could } \\
\text { be considered. }\end{array}$ \\
\hline 4 & Mittal et al, [49] & $\begin{array}{lr}\text { Edge detection } & \text { algorithm } \\
\text { using } & \text { multiple } \\
\text { thresholding } & \text { (B-edge) } \\
\text { techniques } & \end{array}$ & $\begin{array}{l}\text { Ability to detect robust and } \\
\text { thin edges with reduced } \\
\text { noise proportion }\end{array}$ & $\begin{array}{l}\text { The algorithms } \\
\text { cannot efficiently } \\
\text { work on blur images }\end{array}$ & $\begin{array}{l}\text { Deep learning approach can be } \\
\text { proposed to reduce the } \\
\text { computational time of the } \\
\text { algorithms }\end{array}$ \\
\hline 5 & Yao [50] & $\begin{array}{l}\text { MM-Sobel edge detector } \\
\text { technique }\end{array}$ & $\begin{array}{l}\text { Efficient algorithms } \\
\text { capable of detecting edges } \\
\text { of the image with low } \\
\text { computational time }\end{array}$ & $\begin{array}{l}\text { The algorithm is } \\
\text { sensitive to noise }\end{array}$ & $\begin{array}{l}\text { Canny edge detection could be } \\
\text { used to improve the accuracy of } \\
\text { detection }\end{array}$ \\
\hline 6 & Aslam et al, [51] & $\begin{array}{lr}\text { Improved } & \text { Sobel edge } \\
\text { detection } & \text { algorithm } \\
\text { combined } & \text { with image } \\
\text { dependent } & \text { thresholding } \\
\text { approach. } & \end{array}$ & $\begin{array}{l}\text { A better performance of } \\
\text { image segmentation over } \\
\text { conventional segmentation } \\
\text { algorithms }\end{array}$ & $\begin{array}{l}\text { Difficult in detecting } \\
\text { closed contour } \\
\text { regions of the } \\
\text { images. }\end{array}$ & $\begin{array}{l}\text { Future work can be explored using } \\
\text { an approach to improve closed } \\
\text { contour algorithm in order to } \\
\text { increase the region area and } \\
\text { reduce the thickness of boundary } \\
\text { lines of regions }\end{array}$ \\
\hline 7 & $\begin{array}{l}\text { Varadarajan et al, } \\
{[52]}\end{array}$ & $\begin{array}{l}\text { A distributed Canny edge } \\
\text { detection segmentation } \\
\text { technique }\end{array}$ & $\begin{array}{l}\text { Scalable fast detection } \\
\text { algorithm with reduction in } \\
\text { latency capable r of } \\
\text { supporting images and } \\
\text { videos }\end{array}$ & $\begin{array}{l}\text { High computational } \\
\text { cost and time } \\
\text { consuming }\end{array}$ & $\begin{array}{l}\text { A combined algorithms of } \\
\text { segmentation techniques can be } \\
\text { used in real time processing to } \\
\text { improve accuracy of detection }\end{array}$ \\
\hline 8 & $\begin{array}{l}\text { Chithambaram1 } \\
\text { and Perumal [53] }\end{array}$ & $\begin{array}{l}\text { Modified canny edge } \\
\text { detection and artificial } \\
\text { neural network algorithm. }\end{array}$ & $\begin{array}{l}\text { Fast, Accurate and robust } \\
\text { segmentation algorithms } \\
\text { for detection of brain } \\
\text { tumor }\end{array}$ & $\begin{array}{l}\text { High computational } \\
\text { cost in detecting } \\
\text { accuracy }\end{array}$ & $\begin{array}{l}\text { Future research can be explored } \\
\text { using different machine learning } \\
\text { approaches for improving the } \\
\text { accuracy of segmentation } \\
\text { algorithms. }\end{array}$ \\
\hline 9 & Asmaidi [54] & $\begin{array}{l}\text { Sobel edge detection } \\
\text { technique }\end{array}$ & $\begin{array}{l}\text { Accurate } r \text { segmentation } \\
\text { with different mean } \\
\text { squared error results for } \\
\text { flowers image. }\end{array}$ & $\begin{array}{l}\text { Highly sensitive to } \\
\text { noise }\end{array}$ & $\begin{array}{l}\text { Algorithms for improving image } \\
\text { acquisition qualities for improving } \\
\text { segmentation accuracy can be } \\
\text { proposed. }\end{array}$ \\
\hline 10 & Ratnam et al [55] & $\begin{array}{l}\text { Canny edge detector } \\
\text { algorithm }\end{array}$ & $\begin{array}{l}\text { Robust and reliable } \\
\text { segmentation output for } \\
\text { detecting brain tumor in } \\
\text { MR image }\end{array}$ & It is time consuming & $\begin{array}{l}\text { The algorithm can be extended to } \\
\text { identification of } 3 \mathrm{D} \text { image } \\
\text { processing. }\end{array}$ \\
\hline
\end{tabular}


Edge based image segmentation is a method that is centered on discontinuities detection .The algorithms are simple to implement and can give an accurate segmentation with good results even in a noisy environment and work well on low quality images than other segmentation algorithms. The limitation of the technique is its high computational complexity in terms of time and memory management.

iv. Threshold Based Segmentation: This is the commonest and easiest approach used in medical image segmentation. This method is used to convert a grey-scale image to binary image. In this approach threshold value is specified and the image is fragmented into group of pixels having value less than or equal to the Specified threshold value. Threshold based segmentation can be used for images having light objects over darker background. Global and Local thresholding are the two most commonly used thresholding approaches [22]. Threshold technique has a fast processing speed. This method will work well when object and background have high contrast. The drawback of this technique is that it is unable to give accurate result when mage has no major grey scale difference or image with overlapping grey scale. Recent studies conducted using this segmentation approach is highlighted in Table 4.

Table 4. Threshold based segmentation techniques.

\begin{tabular}{|c|c|c|c|c|c|}
\hline $\mathrm{S} / \mathrm{N}$ & Author/year & Method & Result & Limitation & Future Work \\
\hline 1 & $\begin{array}{l}\text { Dash and } \\
\text { Bhoi [56] }\end{array}$ & $\begin{array}{l}\text { Otsu tresholding } \text { was } \\
\text { used for blood vessel } \\
\text { segmentation } \\
\text { imasing } \\
\text { DRIVE obtained from } \\
\text { databases }\end{array}$ & $\begin{array}{l}\text { Robust segmentation with } \\
\text { less computation time and } \\
\text { easy implementation.. } \\
\text { Highest accuracy of } 0.956 \\
\text { was achieved using DRIVE } \\
\text { database. }\end{array}$ & $\begin{array}{l}\text { Wrong selection of } \\
\text { threshold may lead to } \\
\text { over-segmentation }\end{array}$ & $\begin{array}{lrr}\text { Future } & \text { work can } & \text { be } \\
\text { explore } & \text { using } & \text { fuzzy } \\
\text { based algorithm } & \text { for } \\
\text { blood } & & \text { vessel } \\
\text { segmentation } & & \end{array}$ \\
\hline 2 & $\begin{array}{l}\text { Wang et al } \\
\text { [57] }\end{array}$ & $\begin{array}{l}\text { Two-dimensional Otsu } \\
\text { based on estimation of } \\
\text { distribution } \\
\text { algorithm using guided } \\
\text { filtering }\end{array}$ & $\begin{array}{l}\text { Improved segmentation and } \\
\text { less computational time with } \\
\text { exponential growth. }\end{array}$ & $\begin{array}{l}\text { Limited in handling } \\
\text { images with the same } \\
\text { gray scale range but not } \\
\text { efficient for object with } \\
\text { large gray scale } \\
\text { distribution }\end{array}$ & $\begin{array}{l}\text { Efficient segmentation } \\
\text { techniques could be } \\
\text { adopted so as to } \\
\text { handle more complex } \\
\text { images }\end{array}$ \\
\hline 3 & $\begin{array}{l}\text { Mapayi et al, } \\
{[58]}\end{array}$ & $\begin{array}{l}\text { Thresholding technique } \\
\text { based on gray level co- } \\
\text { occurrence matrix- } \\
\text { energy information for } \\
\text { retinal vessel } \\
\text { segmentation. } \\
\end{array}$ & $\begin{array}{l}\text { A robust and time efficient } \\
\text { segmentation with efficient } \\
\text { accuracy rates }\end{array}$ & $\begin{array}{l}\text { It has assumption of } \\
\text { uniform illumination }\end{array}$ & $\begin{array}{l}\text { The use of soft } \\
\text { Computing and } \\
\text { heuristics approaches } \\
\text { may be adopted in } \\
\text { detecting more thin } \\
\text { vessels. }\end{array}$ \\
\hline 4 & $\begin{array}{l}\text { Jang et al, } \\
{[59]}\end{array}$ & \begin{tabular}{lr} 
Global & thresholding \\
algorithm & \multicolumn{2}{r}{ using } \\
boundary & blocks for \\
extracting & a bimodal \\
histogram. &
\end{tabular} & $\begin{array}{l}\text { Robust image segmentation } \\
\text { method for images with } \\
\text { noise and small objects }\end{array}$ & $\begin{array}{l}\text { The method may not } \\
\text { accurately to handle } \\
\text { large scale images }\end{array}$ & \\
\hline 5 & $\begin{array}{l}\text { Vijay and } \\
\text { patil [60] }\end{array}$ & $\begin{array}{l}\text { Otsu thresholding using } \\
\text { Iteration and Custom } \\
\text { approach }\end{array}$ & $\begin{array}{l}\text { Custom approach showed } \\
\text { better result in segmenting } \\
\text { foreground from background } \\
\text { images. }\end{array}$ & High sensitive to noise & $\begin{array}{l}\text { Histogram thresholding } \\
\text { may be considered for } \\
\text { future research }\end{array}$ \\
\hline 6 & $\begin{array}{l}\text { Telgad et al, } \\
{[61]}\end{array}$ & $\begin{array}{ll}\text { Global thresholding } \\
\text { algorithms }\end{array}$ & $\begin{array}{l}\text { Simple, fast and accurate } \\
\text { segmentation for fingerprint } \\
\text { minutiae extractions }\end{array}$ & $\begin{array}{l}\text { Texture of the image if } \\
\text { not well preprocessed } \\
\text { may } \quad \text { affect } \\
\text { segmentation result }\end{array}$ & $\begin{array}{l}\text { Otsu method and PCA } \\
\text { algorithms may be used } \\
\text { to accurately de-noised } \\
\text { the image. }\end{array}$ \\
\hline 7 & $\begin{array}{l}\text { Gurung and } \\
\text { tamang [62] }\end{array}$ & $\begin{array}{l}\text { Heuristic approach for } \\
\text { image segmentation to } \\
\text { determine multilevel } \\
\text { thresholds by sampling } \\
\text { the histogram of a digital } \\
\text { image. }\end{array}$ & $\begin{array}{l}\text { Decrease in } \text { CPU } \\
\text { computational time for image } \\
\text { segmentation than Otsu } \\
\text { method with robust images }\end{array}$ & $\begin{array}{l}\text { The approach may not } \\
\text { efficiently be used to } \\
\text { detect all boundaries in } \\
\text { an image }\end{array}$ & $\begin{array}{l}\text { Clustering algorithms } \\
\text { could be applied to detect } \\
\text { image efficiently wilt } \\
\text { less time complexity }\end{array}$ \\
\hline 8 & $\begin{array}{l}\text { Srinivas } \\
\text { al, [63] }\end{array}$ & $\begin{array}{ll}\text { Otsu } & \text { thresholding } \\
\text { algorithm } & \end{array}$ & $\begin{array}{l}\text { It gives better accuracy in } \\
\text { segmenting the image than } \\
\text { existing algorithms }\end{array}$ & $\begin{array}{l}\text { Highly sensitive to } \\
\text { noise }\end{array}$ & $\begin{array}{l}\text { K-means algorithm could } \\
\text { be proposed for future } \\
\text { studies }\end{array}$ \\
\hline 9 & $\begin{array}{c}\text { Pai et al, } \\
{[64]}\end{array}$ & $\begin{array}{l}\text { Threshold-gradient } \\
\text { based } \quad \text { Segmentation } \\
\text { method }\end{array}$ & $\begin{array}{l}\text { Proposed approach } \\
\text { performed efficiently than } \\
\text { existing algorithms }\end{array}$ & $\begin{array}{l}\text { It neglects spatial } \\
\text { information of an image }\end{array}$ & $\begin{array}{l}\text { Convolutional neural } \\
\text { network algorithms } \\
\text { could be used to improve } \\
\text { the results }\end{array}$ \\
\hline 10 & $\begin{array}{l}\text { Patil and } \\
\text { Shaikh [65] }\end{array}$ & $\begin{array}{l}\text { Otsu thresholding using } \\
\text { L*a*b color space }\end{array}$ & $\begin{array}{l}\text { Good segmentation result for } \\
\text { flower images as compared } \\
\text { to the state of the art. }\end{array}$ & $\begin{array}{l}\text { It is sensitive to noise } \\
\text { and selecting wrong } \\
\text { threshold can hindered } \\
\text { segmentation results. }\end{array}$ & $\begin{array}{l}\text { Feature extraction such } \\
\text { as color shape and } \\
\text { texture can be performed } \\
\text { on segmented image to } \\
\text { improve accuracy of } \\
\text { detection. }\end{array}$ \\
\hline
\end{tabular}


Thresholding is a popular method of image segmentation used in discriminating background from foreground images; it is a simple, fast, easy technique with low computational time and does not normally require prior information of the image before segmentation. The algorithm is efficient and robust in its detention. The weakness of this algorithm is that it does not work fast with wide range of images. Threshold selection is a crucial step of this method, selecting the wrong threshold may leads to over segmentation of the algorithm and cause inaccurate segmentation results.

\section{Methodology}

The process of femur bone image processing as depicted in Figure 1 consists of the image segmentation techniques employed in this study which includes edge based detection, thresholding, region growing and deformable model. The performance of these algorithms were investigated on the input image and comparison were made between the four segmentation techniques to determine the best performing among them that could be used in bone image segmentation for making intelligent decisions.

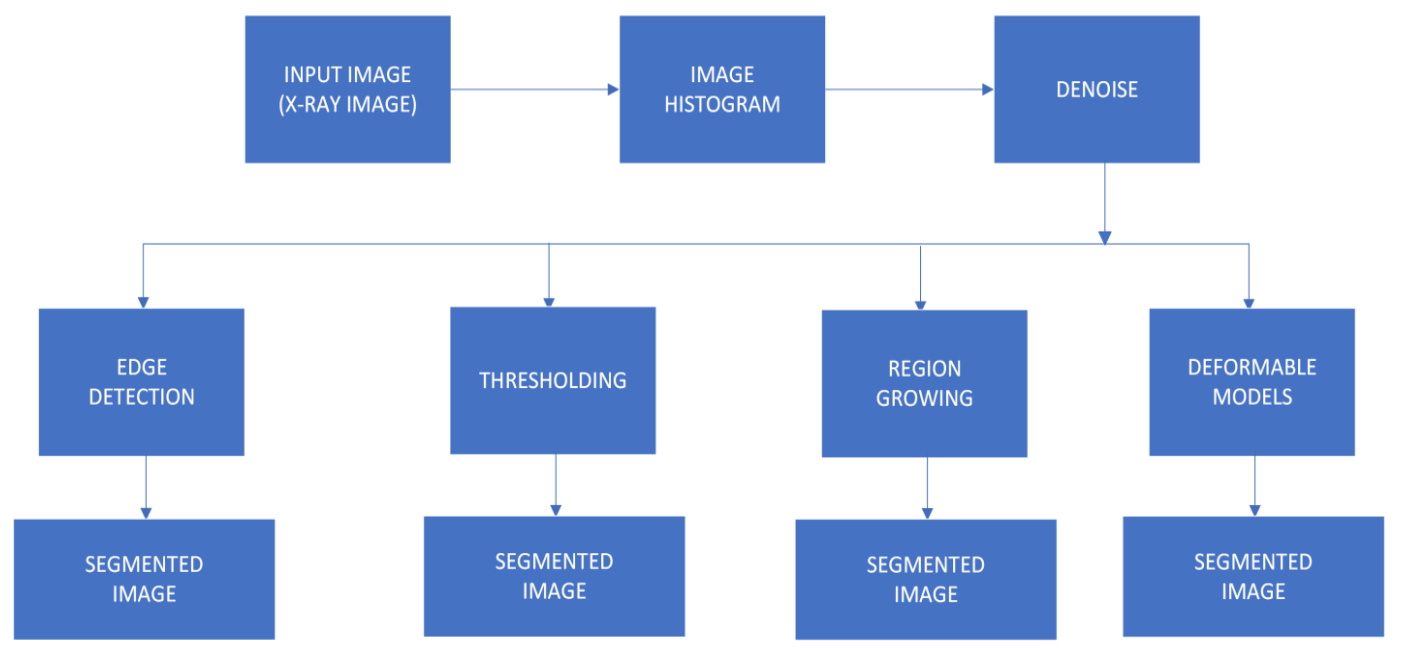

Fig. 1. The process of femur bone image segmentation

\subsection{Experimental Description}

The experiment was carried out in MATLAB. 9.7.0 Programming environment. Femur X-Ray image was used as the input image for image segmentation. The femur bone image as depicted in Fig. 2 was taken at $53 \mathrm{kV}$ and digitized at 7 bit/pixel using a charge-coupled device (CCD) camera with a size of 410 by 500 resolutions. Thereafter it was observed that the intensity level of the image was not widely dispersed. To correct this anomalies caused by uneven illumination in the image, histogram generation was used to enhanced the appearance of the images by mapping the input image to the output image such that its histogram is uniform after mapping. This pre-processing step partially eliminates the intensity variations between images.

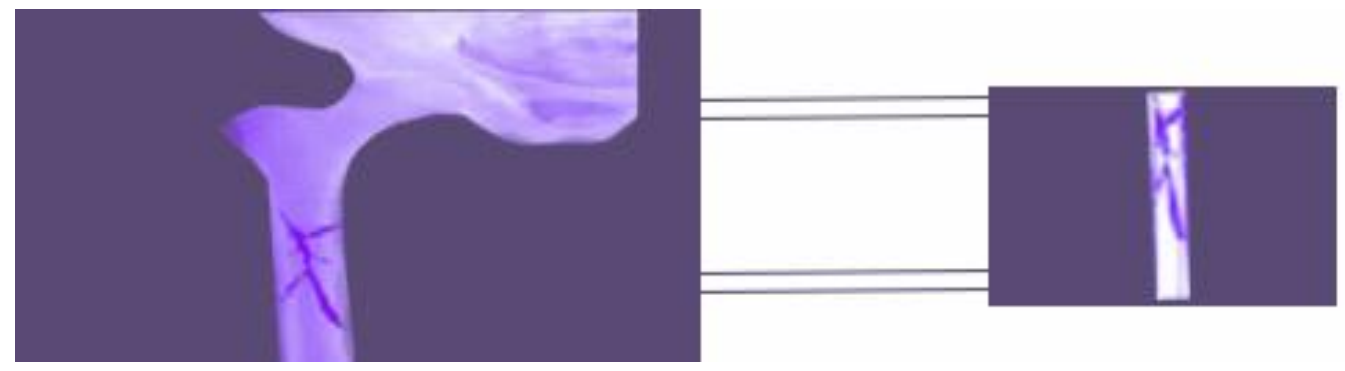

Fig. 2. X-ray Femur Image (input Image)

As part of the preprocessing techniques needed to remove noise that can affect the performance of image segmentation algorithms, the image was converted into binary form where each gray level image was quantized into bits consisting of ' 0 ' as black pixel and ' 1 ' as white pixel by separating femur shaft image from soft tissue shade pixel. A non-linear digital image filtering approach known as median filter was used to suppress isolated noise while preserving the femur bone border edge. After image pre-processing stage, the input image was processed with four different segmentation algorithms whose performance were measured to determine the best performing approach and classical model that can robustly handle femur bone image segmentation problem. 


\section{Results of the Different Segmentation Techniques on Femur Bone Image}

The following section shows the results of the four segmentation techniques used in the study which are Edge detection, Thresholding, Region growing and deformable model.

i. Thresholding: Global image thresholding in equation 1 and 2 respectively were applied on the input image to determine the optimal value to distinguish the region of interest (the bone image) from the background (Xray image using Otsu's method of thresholding. This technique was based on the interclass variance maximization so that threshold classes will have a well discriminated intensity values.

$$
T=T[a, b, q(a, b), r(a, b)
$$

Where $\mathrm{T}$ denotes the threshold value, $\mathrm{a}, \mathrm{b}$ represented the coordinate of the threshold value point. $\mathrm{q}(\mathrm{a}, \mathrm{b}), \mathrm{r}(\mathrm{a}, \mathrm{b})$ symbolized the points of the gray level images. Threshold image $h(a, b)$ can further be expressed as denoted in equation 4

$$
\left\{\begin{array}{l}
1 \text { if } r(a, b)>1 \\
0 \text { if } r(a, b) \geq 0
\end{array}\right.
$$

Fig. 3 depicts result obtained after applying Otsu method of thresholding on the input image.

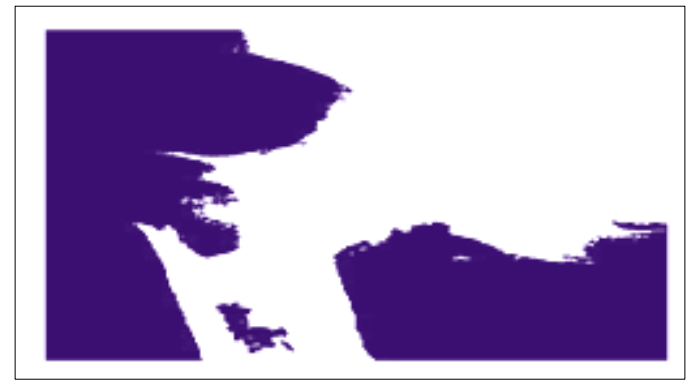

Fig. 3. Otsu method of thresholding

ii. Edge based segmentation: This algorithm uses edge detectors to find edges in the image. The study adopted five based edge detectors techniques such as, canny operator, prewitt operator, sobel operator, Roberts operators and log (laplacian) operator which were applied on the input image and comparison were made among the edge based segmentation algorithms used in the study to ascertain the best edge detector techniques. Fig. 4 depicts the output of various edge based segmentation techniques used in the study. Analysis of the visual inspection of the experimental results obtained from the images denotes that Prewitt operator gives a similar image as obtained in Sobel and Roberts. Canny and Log also showed similar image which perfectly detects all the edges in the image (flesh and bones) and can be seen as the most effective method for detecting edges of the input image using edge based segmentation.

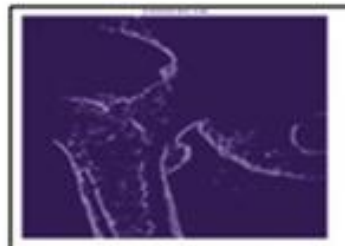

Prewitt Operator

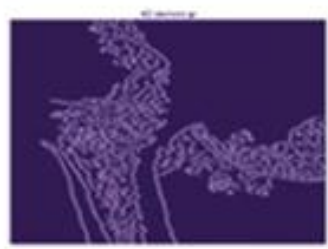

Canny Operator

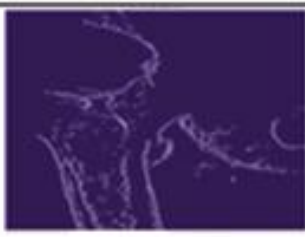

Sobel Operator

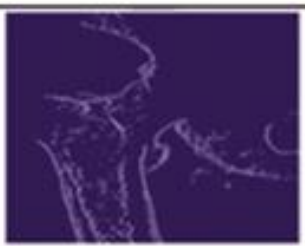

Roberts Operator

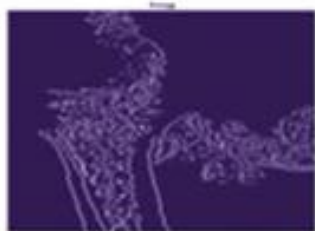

Log Operator

Fig. 4. Edge based segmentation algorithms output 
iii. Region-growing segmentation: The use of region growing segmentation adds neighboring pixels to the regions of femur bone with similar image features, thereby growing the regions. The anatomical structure of femur bone using this approach is depicted in Fig. 5.

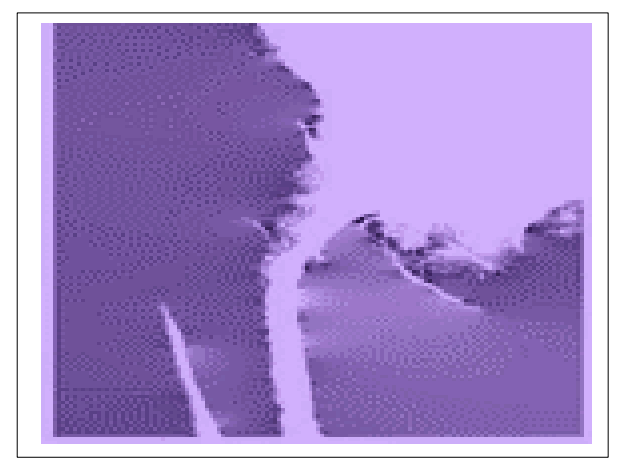

Fig. 5. Region growing segmentation on input image

iv. Active contour model: Snake model of active contour model in medical image segmentation works by identifying the region of interest (ROI) under consideration (Femur bone) [66,26]. This model uses the application of spline to decrease the energy in ROI by different internal and external forces that is affecting the image based on suitable contour features. It propagates through the region of intrest of input image to lessen the energy function and dynamically move to the local minimum as expressed in equation 3.

$$
g(m, o)=(q(m, 0), r(m, o)
$$

Where the coordinate of the two dimensional curve is denoted by $\mathrm{q}$ and $\mathrm{r}$, given that $\mathrm{g}$ denotes the spline parameters that ranges from $[0-1, \mathrm{~m}$ symbolize the linear parameter $\in[0,1]$ and o represent the time parameter $\in[0, \infty]$.

The total energy $\left(T_{e}\right)$ used by the snake model in identification of the image features is expressed as represented in equation 4 ;

$$
T_{e}=I_{e}+E_{e}+E_{u}
$$

Where $I_{e}$ denotes the internal energy of the snake model which relies on the degree of the spline connecting to the shape of the target image which explains piecewise smoothness factors in the contour, $E_{e}$ represent the external energy specified by the user and $E_{u}$ is the energy of the femur bone image under consideration that moves valuable data on the illumination of the spline signifying the target object.

The internal energy of snake active contour model for detecting region of interest (Femur bone image) in the study can further be expressed as depicted in equation 5 .

$$
\alpha / \frac{\delta v}{\delta s} /^{2+} \beta / \frac{\delta^{2} v}{\delta s^{2}} /
$$

Given that $\alpha$ denotes how far the snake will be protracted and the capacity of elasticity possible for the snake while $\beta$ is use to determine the rigidity level for the snake needed in bone processing. Fig. 6 represent the output of active contour model using snake model as it perfectly detected the smooth shape in the femur image.

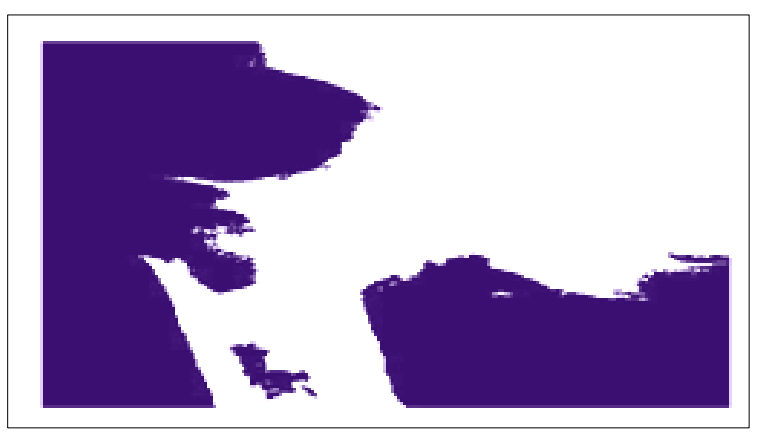

Fig. 6. Active contour model (snake model) 


\subsection{Discussions of the Results}

From the results obtained above, Thresholding technique of bone image processing is one of the simplest segmentation techniques, but it is difficult to threshold noisy images as the background intensity and the foreground intensity could not be distinctly separated making it difficult to estimate the threshold for each sub-image. Edge based used different edge detector techniques, but it was observed from the study that the edges extracted by edge-based algorithms were disjointed and could not completely represent the boundary of an object. However, region growing algorithms as used in the study proved to be efficient and hence, a reliable approach that could be used in femur bone image processing for detecting ROI. It was also observed that these techniques have over-segmentation tendency in processing the input image and are sensitive to noise. Deformable techniques were less sensitive to noise if well preprocessed than the other model considered in the study. This makes them more suitable for complex medical bone image segmentation problems. Based on the results of the implementations, it has shown that Thresholding, Edge-based, Region based techniques have the capabilities to solve simple medical bone image segmentation problems. However, in case of complex bone images segmentation problems, which cannot be tackled effectively by classical image segmentation approaches, deformable model is the most suitable approach.

\section{Conclusion}

In this study, we have identified the strengths and weaknesses of different segmentation techniques and we have also implemented the segmentation techniques on femur bone image to detect the most promising among them and their results have been presented. For the examination of the segmentation techniques, femur bone image was used as input. All implementations were carried out in MATLAB 9.7.0 programming environment. From the visual results, Active contour model using snake model came out as the most efficient technique that can be used in segmenting input data (Femur image) than the other medical image segmentation approaches implemented in the study. This is because it was able to perfectly detect the smooth shape in the femur image presented to it. Therefore, automatic segmentation of medical bone images for diagnosis and assessment can be accomplished using active contour model. Also, it was observed that the effectiveness of diverse segmentation techniques depends on the nature of image modality, characteristics of region of interest and application.

However, in image processing and computer vision, segmentation is still a challenging issue for many real life applications and hence more innovative work is required. Future work can be explored in the areas of combining geometric techniques for active contours model and deep learning approach to overcome the limitations of some of the existing approaches.

\section{References}

[1] Saini, S., \& Arora, K. (2014). A study analysis on the different image segmentation techniques. International Journal of Information \& Computation Technology, 4(14), 1445-1452.

[2] Shiv Gehlot, John Deva Kumar,"The Image Segmentation Techniques", International Journal of Image, Graphics and Signal Processing(IJIGSP), Vol.9, No.2, pp.9-18, 2017.DOI: 10.5815/ijigsp.2017.02.02.

[3] Kumar, S., Lenin , F., Muthukumar, s., Ajay , K., and Sebastian , V. (2018). A voyage on medical image segmentation algorithms. Computational Life Sciences and Smarter Technological Advancement, Special Issue: 75-87.

[4] L.Sankari,C.Chandrasekar,"A New Enhanced Semi Supervised Image Segmentation Using Marker as Prior Information", IJIGSP, vol.4, no.1, pp.51-56, 2012..

[5] Dorgham, O., Osama, M., Stephen, D., Laycock, O., and Mark, H. (2012). GPU accelerated generation of digitally reconstructed radiographs for 2-D/3-D image registration. IEEE Transactions on biomedical engineering, 59(9), 25942603.

[6] Mandeep , K., and Jindal, G. (2011). Medical Image Segmentation using Marker Controlled Watershed Transformation. International journal of Computer Science and Technology, 2(1), 1-6.

[7] Huiyu, Z., Jiahua, W., and Jianguo, Z. (2010). Digital Image Processing Part II, 2nd edition. London, United Kingdom: Ventus Publishing APS.

[8] Farzaneh Nikroorezaei, Somayeh Saraf Esmaili, " Application of Models based on Human Vision in Medical Image Processing: A Review Article", International Journal of Image, Graphics and Signal Processing (IJIGSP), Vol.11, No.12, pp. 23-28, 2019.DOI: 10.5815/ijigsp.2019.12.03.

[9] Osama , D., Mohammad , J., Mohammad , H., and Ammar , A. (2018). Proposed Method for Automatic Segmentation of Medical Images. International Arab Confrence on Infornation Technology, Lebanon: IEEE.pp. 1-9

[10] Zhao, C., Han, J., Jia, Y., Fan, L., and Gou, F. (2018). Versatile Framework for Medical Image Processing and Analysis with Application to Automatic Bone Age Assessment. Journal of Electrical and Computer Engineering, 1(2), 1-14.

[11] Senthilkumaran, N., and Vaithegi , S. (2016). Image Segmentation by Using Thresholding Techniques for Medical Images. International Journal of Computer Science and Engineering, 6(1), 1-13.

[12] Anithadevi, D., and Perumal, K. (2016). A Hybrid Approach Based Segmentation Technique for Brain Tumor in MRI Images. International Jpournal of Signal and Image Processing, 17(1), 1-10.

[13] Farmaha, I., Banas, M., Lukashchuk, V., and Farmaha, T. (2019). Wound image segmentation using clustering based algorithms. New Trends in Production Engineering, 2(1), 570-578. 
[14] Bansal, S., Kaur, S., and Kaur, N. (2019). Enhancement in Brain image segmentation using Swarm Ant Lion Algorithm. International Journal of Innovative Technology and Exploring Engineerin, 8(10), 1-6.

[15] Tian, Z., Si, X., Zheng, Y., Chen, Z., and Li, X. (2020). Multi-step medical image segmentation based on reinforcement learning. Journal of Ambient Intelligence and Humanized Computing, 1(2), 1-12.

[16] Kant, S., and Bala, S. (2020). Dense Dilate Inception Network for Medical Image Segmentation. international Journal of Advanced Computer Science and Applications, 11(11), 785-793.

[17] Ouyang, C., Biffi, C., Chen , C., Kart, T., Qiu, H., and Rueckert, D. (2020). Self-Supervision with Superpixels: Training Fewshot Medical Image Segmentation without Annotation. Computer Vision and Pattern Recognition, 2(1) 1-19.

[18] Haider, W., Malik, M., Raza, M., Wahab, A., Khan, I., Zia, U., et al. (2012). A hybrid method for edge continuity based on Pixel Neighbors Pattern Analysis (PNPA) for remote sensing satellite. International Journal of Communications, Network and System Sciences, 5(1), 624-630.

[19] Samet, R., Amrahov, E., and Ziroglu, A. (2012). Fuzzy rule-based image segmentation technique for rock thin section images. 3rd International Conference on Image Processing Theory, Tools and Applications (pp. 402-406). IEEE: Istanbul,Turkey.

[20] Khokher, M., Ghafoor, A., and Siddiqui, A. (2012). Image segmentation using fuzzy rule based system and graph cuts. 12th International Conference on Control Automation Robotics \& Vision, Guangzhou, China : IEEE. 1148-1153.

[21] Li, Y., Bai, X., Jao, L., and Xue, Y. (2017). Partitioned-cooperative quantum-behaved particle swarm optimization based on multilevel thresholding applied to medical image segmentation. Journal of Applied Soft Computing, 56(1), 345-356.

[22] Rouhi, R., Jafari , M., Kasaei, S., and Keshavarzian, P. (2014). Benign and malignant breast tumors classification based on region growing and CNN segmentation. Expert Systems With Application, 42(3), 990-1002.

[23] Tyan, Y., Wu , M., Chin, C., Kuo, Y., Lee, M., and Chang, H. (2014). Ischemic stroke detection system with a computer-aided diagnostic ability using an unsupervised feature perception enhancement method. International Journal of Biomedical Imaging, 12(2), 1-6.

[24] Aganj, I., Harisinghani, M., Weisslede, R., and Fischi, B. (2018). Unsupervised Medical Image Segmentation Based on the Local Center of Mass. Journal of Scientific Report, 8(1), 1-8.

[25] Dar, S. A., and Padha, D. (2019). Medical Image Segmentation: A Review of Recent Techniques, Advancements and a Comprehensive Comparison. International Journal of sComputer Sciences and Engineering, 7(7), 114-124.

[26] Li, C., Liu, L., Sun, X., Zhao, J., and Yin, J. (2019). Image segmentation based on fuzzy clustering with cellular automata and features weighting. EURASIP Journal on Image and Video Processing, 2019(1), 1-11.

[27] Lei, T., Liu, P., Jia, X., Zhang, X., Meng, H., and Nandi, A. K. (2019). Automatic fuzzy clustering framework for image segmentation. IEEE Transactions on Fuzzy Systems, 28(9), 2078-2092

[28] Qureshi, M. N., and Ahamad, M. V. (2018). An improved method for image segmentation using K-means clustering with neutrosophic logic. Procedia computer science, 132, 534-540.

[29] Bora, D. J., and Gupta, A. K. (2015). A novel approach towards clustering based image segmentation. arXiv preprint arXiv:1506.01710.

[30] Hassan, M. R., Ema, R. R., and Islam, T. (2017). Color image segmentation using automated K-means clustering with RGB and HSV color spaces. Global Journal of Computer Science and Technology.

[31] Saravanan, M., Kalaivani, B., and Geethamani, R. (2017). Image Segmentation Using K-means clustering based thresholding algorithm. International journal of advanced technology in Engineering and science, 5(2).

[32] Panda, S. (2015). Color Image Segmentation Using K-means Clustering and Thresholding Technique. Interntional journal of ESC, 1132-1136.

[33] Dubey, S. R., Dixit, P., Singh, N., and Gupta, J. P. (2013). Infected fruit part detection using K-means clustering segmentation technique.

[34] Inbarani H, Hannah, and Ahmad Taher Azar. "Leukemia image segmentation using a hybrid histogram-based soft covering rough k-means clustering algorithm." Electronics 9, no. 1 (2020): 188.

[35] Wang, Yun Shi Xuqi, and Shanwen Zhang. "Plant Disease Leaf Image Segmentation Using K-Means Clustering Based on Internet of Things." (2016).

[36] Shimodaira, H. (2017). Automatic color image segmentation using a square elemental region-based seeded region growing and merging method. arXiv preprint arXiv:1711.09352.

[37] Yuan, Y., Chen, D., and Yan, L. (2015). Interactive three-dimensional segmentation using region growing algorithms. Journal of Algorithms \& Computational Technology, 9(2), 199-213.

[38] Kaur, G., and Jindal, S. Region growing image segmentation on large datasets using gpu. International journal, 15(14).

[39] Jaber, I. M., Jeberson, W., and Bajaj, H. K. (2006). Improved region growing based breast cancer image segmentation. International Journal of Computer Applications, 975, 888

[40] Kansal, S., and Jain, P. (2015). Automatic seed selection algorithm for image segmentation using region growing. International Journal of Advances in Engineering \& Technology, 8(3), 362.

[41] Shewale, T. P., and Patil, S. B. (2016). Detection of brain tumor based on segmentation using region growing method. Int. J. Eng. Innov. Res, 5(2), 173-176.

[42] Biratu, E. S. S., Schwenker, F., Debelee, T. G. G., Kebede, S. R. R., Negera, W. G. G., and Molla, H. T. T. (2021). Enhanced Region Growing for Brain Tumor MR Image Segmentation. Journal of Imaging, 7(2), 22.

[43] Udayakumar, E., Santhi, S., Gowrishankar, R., Ramesh, C., and Gowthaman, T. (2016). Region growing image segmentation for newborn brain MRI. Biotechnology: An Indian Journal Trade Sci Inc, 12, 1-8.

[44] Jain, P. K., and Susan, S. (2013, December). An adaptive single seed based region growing algorithm for color image segmentation. In 2013 Annual IEEE India Conference (INDICON) (pp. 1-6). IEEE.

[45] Thukral, T., Verma, S., Gaur, S., and Tyagi, N. Segmentation of Lung Cancer using Mark Region Growing and Median Filter. International Journal of Computer Applications, 975, 8887.

[46] Padmapriya, B., Kesavamurthi, T., and Ferose, H. W. (2012). Edge based image segmentation technique for detection and estimation of the bladder wall thickness. Procedia engineering, 30, 828-835. 
[47] Kharrofa, S. H. A. (2018). Segmentation of Images by Using Edges Detection Techniques. Iraqi Journal of Information Technology. V, 8(3).

[48] Cao, J., Chen, L., Wang, M., and Tian, Y. (2018). Implementing a parallel image edge detection algorithm based on the Otsucanny operator on the Hadoop platform. Computational intelligence and neuroscience, 2018.

[49] Mittal, M., Verma, A., Kaur, I., Kaur, B., Sharma, M., Goyal, L. M., ... and Kim, T. H. (2019). An efficient edge detection approach to provide better edge connectivity for image analysis. IEEE Access, 7, 33240-33255

[50] Yao, Y. (2016). Image segmentation based on Sobel edge detection. In 2016 5th International Conference on Advanced Materials and Computer Science (ICAMCS 2016). Atlantis Press.

[51] Aslam, A., Khan, E., and Beg, M. S. (2015). Improved edge detection algorithm for brain tumor segmentation. Procedia Computer Science, 58, 430-437.

[52] Xu, Q., Varadarajan, S., Chakrabarti, C., and Karam, L. J. (2014). A distributed canny edge detector: algorithm and FPGA implementation. IEEE Transactions on Image Processing, 23(7), 2944-2960.

[53] Chithambaram, T., and Perumal, K. (2016). Edge detection algorithms using brain tumor detection and segmentation using artificial neural network techniques. International Research Journal of Advanced Engineering and Science, 1(3), 135-140.

[54] Asmaidi, A., Putra, D. S., and Risky, M. M. (2019). Implementation of sobel method based edge detection for flower image segmentation. Sinkron: Jurnal dan Penelitian Teknik Informatika, 3(2), 161-166.

[55] Ratnam, S. S., Kumar, D. S., and Madhukar, K. (2015). Implementation of Edge Detection Technique for Identification and Evaluation of Brain Tumor Metrics in MR Image through Lab VIEW.

[56] Dash, J., and Bhoi, N. (2018, January). Retinal blood vessel segmentation using Otsu thresholding with principal component analysis. In 2018 2nd International Conference on Inventive Systems and Control (ICISC) (pp. 933-937). IEEE

[57] Wang, W., Duan, L., and Wang, Y. (2017). Fast image segmentation using two-dimensional Otsu based on estimation of distribution algorithm. Journal of Electrical and Computer Engineering, 2017.

[58] Mapayi, T., Viriri, S., and Tapamo, J. R. (2015). Adaptive thresholding technique for retinal vessel segmentation based on GLCM-energy information. Computational and mathematical methods in medicine, 2015.

[59] Jang, J. W., Lee, S., Hwang, H. J., and Baek, K. R. (2013, October). Global thresholding algorithm based on boundary selection. In 2013 13th International Conference on Control, Automation and Systems (ICCAS 2013) (pp. 704-706). IEEE.

[60] Vijay, P. P., and Patil, N. C. (2016). Gray scale image segmentation using OTSU Thresholding optimal approach. Journal for Research, 2(05).

[61] Telgad, R., Siddiqui, A. M., and Deshmukh, P. D. (2014). Fingerprint image segmentation using global thresholding. International Journal of Current Engineering and Technology, 4(1), 216-9.

[62] Gurung, A., and Tamang, S. L. (2019). Image segmentation using multi-threshold technique by histogram sampling. arXiv preprint arXiv:1909.05084.

[63] Srinivas, C. H. V. V. S., Prasad, M. V. R. V., and Sirisha, M. Remote Sensing Image Segmentation using OTSU Algorithm. International Journal of Computer Applications, 975, 8887.

[64] Pai, P. Y., Chang, C. C., Chan, Y. K., Tsai, M. H., and Guo, S. W. (2012). An Image Segmentation-Based Thresholding Method. Journal of Imaging Science and Technology, 56(3), 30503-1.

[65] Patil, A. B., and Shaikh, J. A. (2016). OTSU thresholding method for flower image segmentation. International Journal of Computational Engineering Research (IJCER), 6(05).

[66] Hemalatha, R., Thamizhvani, T., Dhivya, J., Joseph, J., Babu, B., and Chandrasekaran, R. (2018). Active Contour Based Segmentation Techniques forMedical Image Analysis. Robert Koprowski, Intech Open. http://dx.doi.org/10.5772/intechopen.7457.

\section{Authors' Profiles}

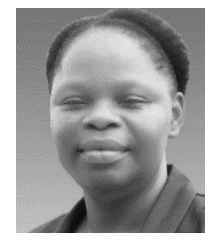

Folasade O. Isinkaye received her BSc in Computer Science from Ondo State University (EKSU), Ado-Ekiti, MSc and $\mathrm{PhD}$ in Computer Science from the University of Ibadan, Oyo State, Nigeria. She is a Senior Lecturer in the Department of Computer Science, Ekiti State University, Ado-Ekiti, Nigeria. Her research interests include Recommender Systems, Data Mining, Machine Learning and Information Systems. She is a member of professional bodies which include, Computer Professionals (Registration Council of Nigeria (CPN)) and Association for Computing Machinery (ACM). She was a visiting PhD scholar at the Laboratory for Knowledge Management, Politecnico di Bari, Italy.

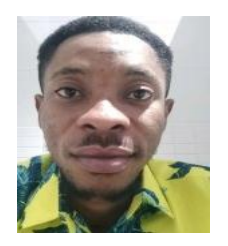

Abiodun G. Aluko had a BSc degree in Computer Science from Ekiti State University, Ado-Ekiti, Nigeria. He is an experienced Information Technologist with different IT roles which include Data Protection on Windows and Linux machine, Microsoft Office 365, Application Lifecycle Management, IT Management, IT Support, IT Service Monitoring with technical knowledge in Cloud Computing. He has worked for some private companies which include Tee Vision Technologies, Fidelity Bank Plc and currently, he is working with Tek Experts as a Software Support Engineer on behalf of its client Micro Focus (Formerly HP/Hewlett Packard Enterprise), He has various certifications in Microsoft, Linux, Oracle, and Microfocus. 
Olayinka A. Jongbo obtained both his BSc (Ed) and MSc in Computer Science from the prestigious Ekiti State University, Ado-Ekiti, Ekiti State, Nigeria. His research interest lies within the areas of Machine Learning, Data Mining, Image Processing and Big Data Analytics. He has publications in reputable peer-reviewed journals.

How to cite this paper: Folasade Olubusola Isinkaye, Abiodun Gabriel Aluko, Olayinka Ayodele Jongbo, " Segmentation of Medical X-ray Bone Image Using Different Image Processing Techniques", International Journal of Image, Graphics and Signal Processing(IJIGSP), Vol.13, No.5, pp. 27-40, 2021.DOI: 10.5815/ijigsp.2021.05.03 